\title{
The molecular structure of the phosphate mineral chalcosiderite - A vibrational spectroscopic study
}

\author{
Ray L. Frost ${ }^{\mathrm{a}, *}$, Yunfei Xi ${ }^{\mathrm{a}}$, Ricardo Scholz ${ }^{\mathrm{b}}$, Carlos Augusto de Brito Ribeiro ${ }^{\mathrm{b}}$

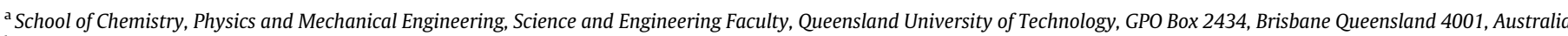 \\ ${ }^{\mathrm{b}}$ Geology Department, School of Mines, Federal University of Ouro Preto, Campus Morro do Cruzeiro, Ouro Preto, MG 35400-00, Brazil
}

\section{H I G H L I G H T S}

- We have studied chalcosiderite $\mathrm{CuFe}_{6}\left(\mathrm{PO}_{4}\right)_{4}(\mathrm{OH})_{8} \cdot 4 \mathrm{H}_{2} \mathrm{O}$ by Raman spectroscopy and by infrared spectroscopy.

- Two phosphate stretching vibrations at 1042 and $1062 \mathrm{~cm}^{-1}$ in line with the two independent phosphate units in the structure.

- The $v_{2}$ and $v_{4}$ bending regions are complex.

- Hydrogen bond distances were calculated.

\section{A R T I C L E I N F O}

\section{Article history:}

Received 8 November 2012

Received in revised form 11 February 2013

Accepted 12 February 2013

Available online 14 March 2013

\section{Keywords:}

Chalcosiderite

Turquoise

Planerite

Faustite

Phosphate

Raman spectroscopy

\section{G R A P H I C A L A B S T R A C T}

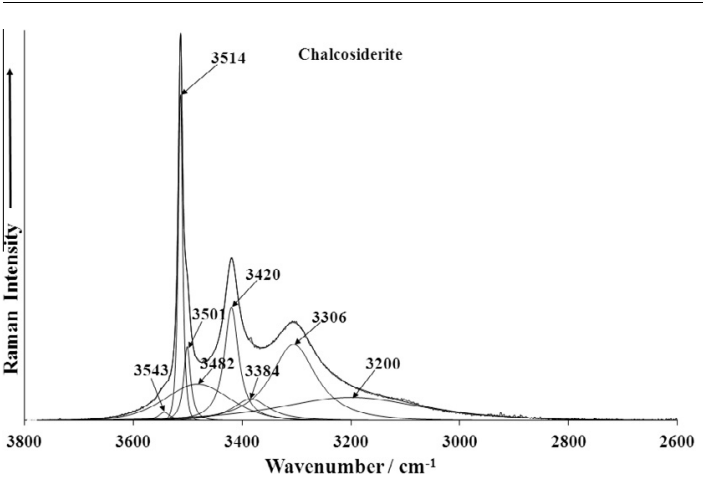

\begin{abstract}
A B S T R A C T
The mineral chalcosiderite with formula $\mathrm{CuFe}_{6}\left(\mathrm{PO}_{4}\right)_{4}(\mathrm{OH})_{8} \cdot 4 \mathrm{H}_{2} \mathrm{O}$ has been studied by Raman spectroscopy and by infrared spectroscopy. A comparison of the chalcosiderite spectra is made with the spectra of turquoise. The spectra of the mineral samples are very similar in the $1200-900 \mathrm{~cm}^{-1}$ region but strong differences are observed in the $900-100 \mathrm{~cm}^{-1}$ region. The effect of substitution of Fe for $\mathrm{Al}$ in chalcosiderite shifts the bands to lower wavenumbers. Factor group analysis (FGA) implies four OH stretching vibrations for both the water and hydroxyl units. Two bands ascribed to water are observed at 3276 and $3072 \mathrm{~cm}^{-1}$. Three hydroxyl stretching vibrations are observed. Calculations using a Libowitzky type formula show that the hydrogen bond distances of the water molecules are $2.74_{5}$ and $2.81_{2} \AA$ A which are considerably shorter than the values for the hydroxyl units $2.89_{6}, 2.91_{7}$ and $2.97_{8} \AA$. Two phosphate stretching vibrations at 1042 and $1062 \mathrm{~cm}^{-1}$ in line with the two independent phosphate units in the structure of chalcosiderite. Three bands are observed at 1102, 1159 and $1194 \mathrm{~cm}^{-1}$ assigned to the phosphate antisymmetric stretching vibrations. FGA predicts six bands but only three are observed due to accidental degeneracy. Both the $v_{2}$ and $v_{4}$ bending regions are complex. Four Raman bands observed at $536,580,598$ and $636 \mathrm{~cm}^{-1}$ are assigned to the $v_{4}$ bending modes. Raman bands at 415, 420, 475 and $484 \mathrm{~cm}^{-1}$ are assigned to the phosphate $v_{2}$ bending modes. Vibrational spectroscopy enables aspects of the molecular structure of chalcosiderite to be assessed.
\end{abstract}

(c) 2013 Elsevier B.V. All rights reserved.

\section{Introduction}

Chalcosiderite is a member of the turquoise mineral group. These are hydrated basic phosphates based upon the formula

\footnotetext{
* Corresponding author. Tel.: +61 73138 2407; fax: +61 731381804.

E-mail address: r.frost@qut.edu.au (R.L. Frost).
}

$\mathrm{AB}_{6}\left(\mathrm{PO}_{4}\right)_{x} \mathrm{PO}_{3}(\mathrm{OH})_{2-x}(\mathrm{OH})_{8} \cdot 4 \mathrm{H}_{2} \mathrm{O}$ where $\mathrm{A}$ is $\mathrm{Ca}, \mathrm{Cu}^{2+}, \mathrm{Fe}^{2+}, \mathrm{Zn}$ and $\mathrm{B}$ is $\mathrm{Al}, \mathrm{Fe}^{3+}$ or $\mathrm{Cr}^{3+}[1]$. The minerals have been known for an extended period of time [2-6]. From an early time, the crystal structure has been explored [7-10]. The minerals are triclinic as is shown in Fig. 1. Cid-Dresdner showed the crystal structure of turquoise, $\mathrm{CuAl}_{6}\left(\mathrm{PO}_{4}\right)_{4}(\mathrm{OH})_{8} \cdot 4 \mathrm{H}_{2} \mathrm{O}$, consists of zig-zag chains of $\mathrm{Al}$ octahedra running in the direction of the $b$ axis and sharing corners with each other and with $\mathrm{P}$ tetrahedra. The $\mathrm{Cu}$ is in 


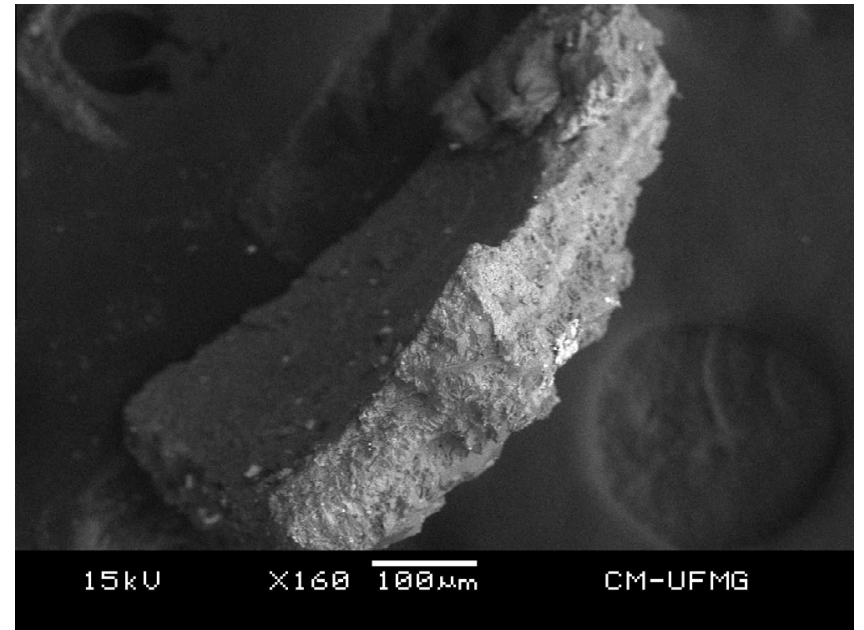

Fig. 1. Backscattered electron image (BSI) of a chalcosiderite single crystal up to $0.5 \mathrm{~mm}$ in length.

distorted octahedral coordination, sharing four edges with four $\mathrm{Al}$ octahedra. Turquoise is the $\mathrm{Al}$ end member and Fe the end member is chalcosiderite.

The amount of published data on the Raman spectra of mineral phosphates is limited. There has been almost no published spectra on the turquoise mineral group [11-13]. The Raman spectra of the hydrated hydroxy phosphate minerals have not been reported. In aqueous systems, Raman spectra of phosphate oxyanions show a symmetric stretching mode $\left(v_{1}\right)$ at $938 \mathrm{~cm}^{-1}$, the antisymmetric stretching mode $\left(v_{3}\right)$ at $1017 \mathrm{~cm}^{-1}$, the symmetric bending mode $\left(v_{2}\right)$ at $420 \mathrm{~cm}^{-1}$ and the $v_{4}$ mode at $567 \mathrm{~cm}^{-1}$ [14-16]. S.D. Ross in Farmer (1974) (page 404) listed some well-known minerals containing phosphate which were either hydrated or hydroxylated or both [17]. The value for the $v_{1}$ symmetric stretching vibration of $\mathrm{PO}_{4}$ units as determined by infrared spectroscopy was given as $930 \mathrm{~cm}^{-1}$ (augelite), $940 \mathrm{~cm}^{-1}$ (wavellite), $970 \mathrm{~cm}^{-1}$ (rockbridgeite), $995 \mathrm{~cm}^{-1}$ (dufrenite) and $965 \mathrm{~cm}^{-1}$ (beraunite). The position of the symmetric stretching vibration is mineral dependent and a function of the cation and crystal structure. The fact that the symmetric stretching mode is observed in the infrared spectrum affirms a reduction in symmetry of the $\mathrm{PO}_{4}$ units. Raman spectroscopy has proven most useful for the study of mineral structure. The objective of this research is to report the Raman and infrared spectra of chalcosiderite and to relate the spectra to the mineral structure.

\section{Experimental}

\section{Samples description and preparation}

The chalcosiderite sample studied in this work was collected from the Siglo XX mine (also named Llallagua), a tin deposit located in the Andes Mountain, Bustillo Province, northern of Potosi department, Bolivia. In the middle of the 20th century Siglo XX was the most productive tin mine in the world. The mine is also an important source for rare and unusual secondary phosphate minerals and is the type locality for a number of rare phosphates such as vauxite, paravauxite, metavauxite and jeanbandyite. The host rock is a conical subvolcanic stock of Tertiary age and the ore deposit is made up of porphyry and porphyry breccias. Hydrothermal alteration was responsible for the replacement of the primary mineralogy and the development of cericitization and tourmalinization [18].

In the Siglo XX mine, light blue to greenish blue chalcosiderite spheres and botryodal aggregates of crystals up to $5.0 \mathrm{~mm}$ in length mainly occur in association or as pseudomorph of paravauxite. Other secondary phosphates such as vivianite, wavellite, metavauxite, sigloite, crandallite and childrenite also can be found in association. The sample was incorporated to the collection of the Geology Department of the Federal University of Ouro Preto, Minas Gerais, Brazil, with sample code SAB-013. An image of the studied sample is presented as Supplementary information (S1). The sample was gently crushed and the associated minerals were removed under a stereomicroscope Leica MZ4. A fragment of pure chalcosiderite was selected and a SEM/EDS image is shown in Fig. 1. The mineral sample was phase analysed by X-ray diffraction.

\section{Scanning electron microscopy (SEM)}

Experiments and analyses involving electron microscopy were performed in the centre of Microscopy of the Universidade Federal

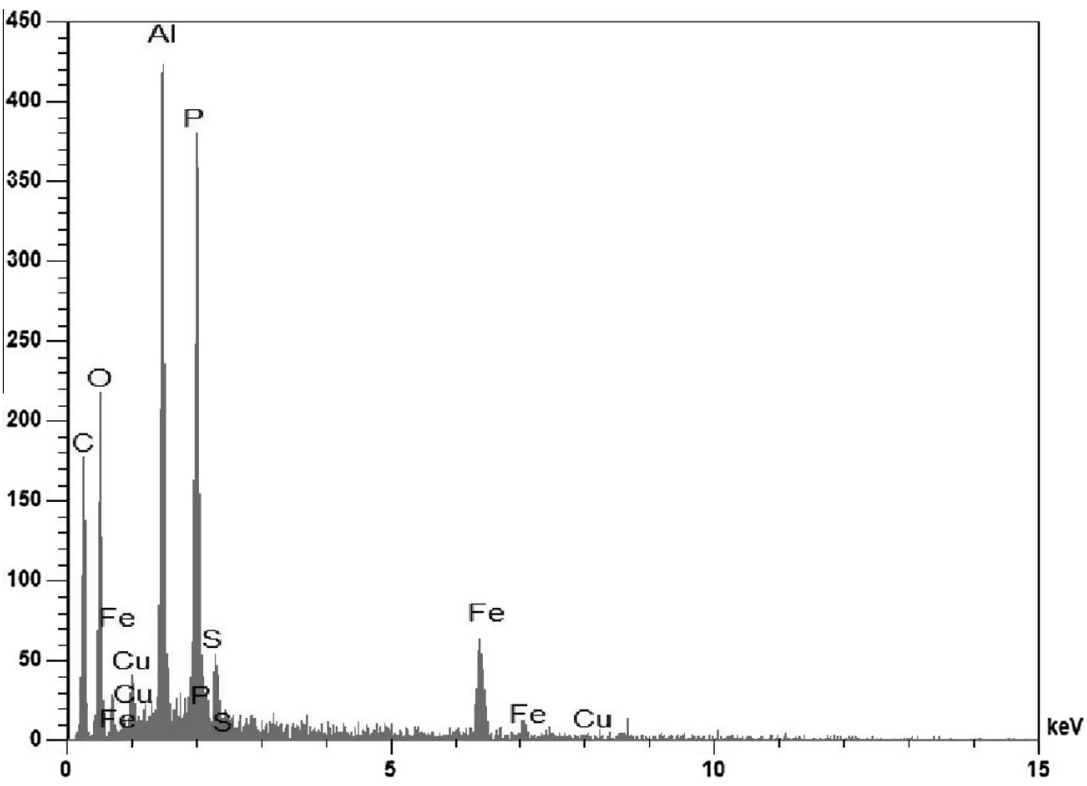

Fig. 2. EDS analysis of chalcosiderite. 
Table 1

Factor group analysis of $2 \times \mathrm{PO}_{4}^{3-}$ vibrations.

\begin{tabular}{lcc}
\hline$T_{\mathrm{d}}$ & $C_{1}$ & $C_{\mathrm{i}}$ \\
\hline $\mathrm{A}_{1}$ & & $9 \mathrm{~A}_{\mathrm{g}}$ \\
$\mathrm{E}$ & $9 \mathrm{~A}$ & $9 \mathrm{~A}_{\mathrm{u}}$ \\
$2 \mathrm{~T}_{2}$ & & \\
\hline
\end{tabular}

de Minas Gerais, Belo Horizonte, Minas Gerais, Brazil (http:// www.microscopia.ufmg.br).

Chalcosiderite crystals were coated with a $5 \mathrm{~nm}$ layer of evaporated carbon. Secondary Electron and Backscattering Electron images were obtained using a JEOL JSM-6360LV equipment. Qualitative and semi-quantitative chemical analyses in the EDS mode were performed with a ThermoNORAN spectrometer model Quest and was applied to support the mineral characterization.

\section{Raman microprobe spectroscopy}

Crystals of chalcosiderite were placed on a polished metal surface on the stage of an Olympus BHSM microscope, which is equipped with $10 \times, 20 \times$, and $50 \times$ objectives. The microscope is
Table 2

Factor group analysis of $2 \times \mathrm{H}_{2} \mathrm{O}$ vibrations.

\begin{tabular}{lll}
\hline$C_{2 \mathrm{v}}$ & $C_{1}$ & $C_{\mathrm{i}}$ \\
\hline $2 \mathrm{~A}_{1}$ & $3 \mathrm{~A}$ & $3 \mathrm{~A}_{\mathrm{g}}$ \\
$\mathrm{B}_{2}$ & & $3 \mathrm{~A}_{\mathrm{u}}$
\end{tabular}

Lattice vibrations

$\Gamma=57 \mathrm{~A}_{\mathrm{u}}+57 \mathrm{~A}_{\mathrm{g}}$

Internal $\mathrm{PO}_{4}^{3-}$ vibrations $=36$

Internal $\mathrm{H}_{2} \mathrm{O}$ vibrations $=12$

Lattice vibrations $=114$

Total vibrations $=162$

$N=55-\mathrm{CuAl}_{6}\left(\mathrm{PO}_{4}\right)_{4}(\mathrm{OH})_{8} \cdot 4 \mathrm{H}_{2} \mathrm{O}$

$3 n-3=3 * 55-3$

part of a Renishaw 1000 Raman microscope system, which also includes a monochromator, a filter system and a CCD detector (1024 pixels). The Raman spectra were excited by a Spectra-Physics model $127 \mathrm{He}-\mathrm{Ne}$ laser producing highly polarised light at $633 \mathrm{~nm}$ and collected at a nominal resolution of $2 \mathrm{~cm}^{-1}$ and a precision of
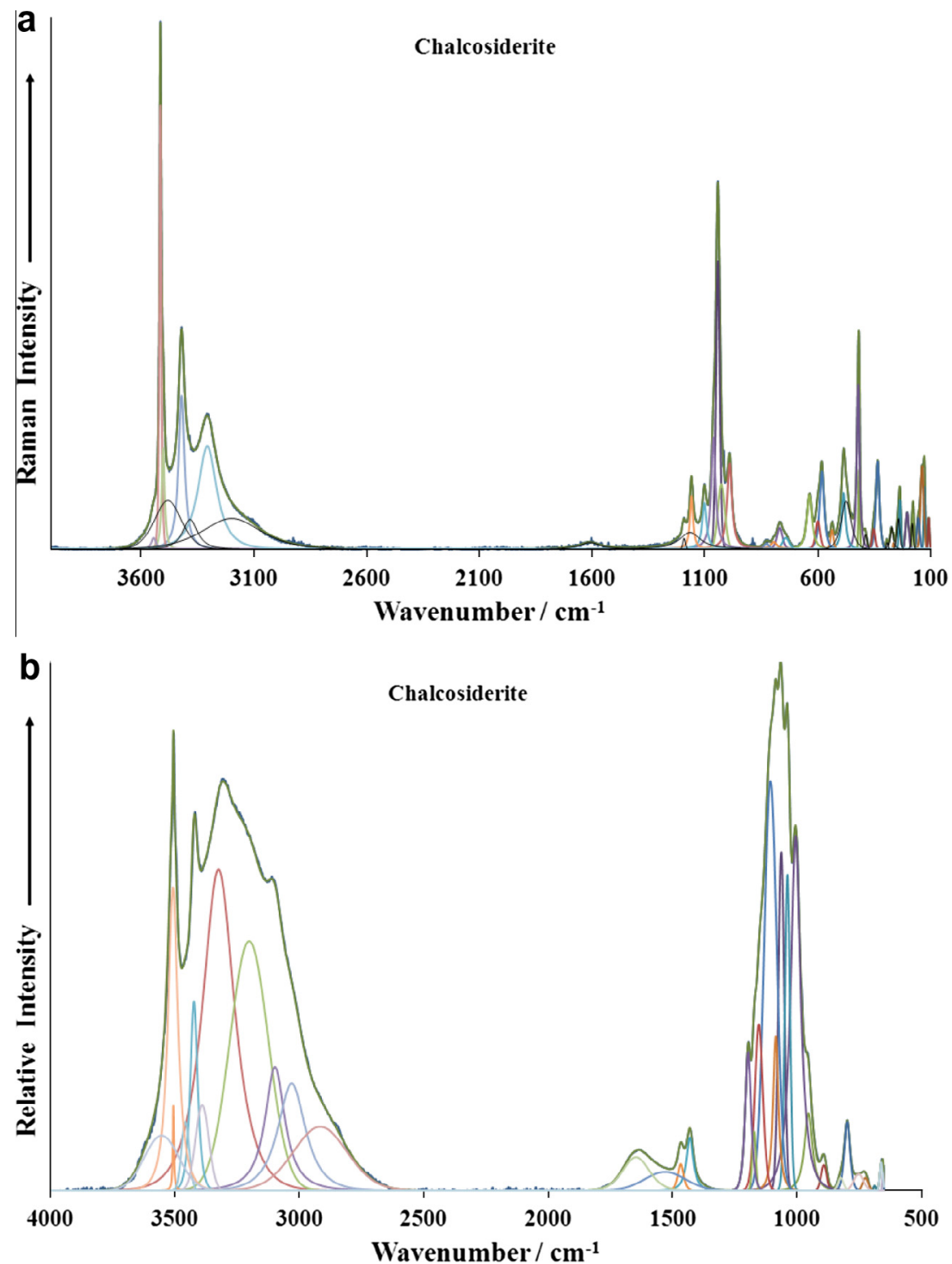

Fig. 3. (a) Raman spectrum of chalcosiderite over the $100-4000 \mathrm{~cm}^{-1}$ spectral range (b) infrared spectrum of chalcosiderite over the $500-4000 \mathrm{~cm}-1$ spectral range. 
$\pm 1 \mathrm{~cm}^{-1}$ in the range between 200 and $4000 \mathrm{~cm}^{-1}$. Repeated acquisitions on the crystals using the highest magnification $(50 \times)$ were accumulated to improve the signal to noise ratio of the spectra. Raman Spectra were calibrated using the $520.5 \mathrm{~cm}^{-1}$ line of a silicon wafer. The Raman spectrum of at least 10 crystals was collected to ensure the consistency of the spectra.

An image of the chalcosiderite crystals measured is shown in Fig. 1. Clearly the crystals of chalcosiderite are readily observed, making the Raman spectroscopic measurements readily obtainable.

\section{Infrared spectroscopy}

Infrared spectra were obtained using a Nicolet Nexus 870 FTIR spectrometer with a smart endurance single bounce diamond ATR cell. Spectra over the $4000-525 \mathrm{~cm}^{-1}$ range were obtained by the co-addition of 128 scans with a resolution of $4 \mathrm{~cm}^{-1}$ and a mirror velocity of $0.6329 \mathrm{~cm} / \mathrm{s}$. Spectra were co-added to improve the signal to noise ratio.
Spectral manipulation such as baseline correction/adjustment and smoothing were performed using the Spectracalc software package GRAMS (Galactic Industries Corporation, NH, USA). Band component analysis was undertaken using the Jandel 'Peakfit' software package that enabled the type of fitting function to be selected and allows specific parameters to be fixed or varied accordingly. Band fitting was done using a Lorentzian-Gaussian cross-product function with the minimum number of component bands used for the fitting process. The Gaussian-Lorentzian ratio was maintained at values greater than 0.7 and fitting was undertaken until reproducible results were obtained with squared correlations of $r^{2}$ greater than 0.995 .

\section{Results and discussion}

\section{Chemical characterization}

The SEM image of chalcosiderite sample studied in this work is shown in Fig. 1. The image shows a fragment of a spherical aggregate. Qualitative chemical analysis shows a homogeneous
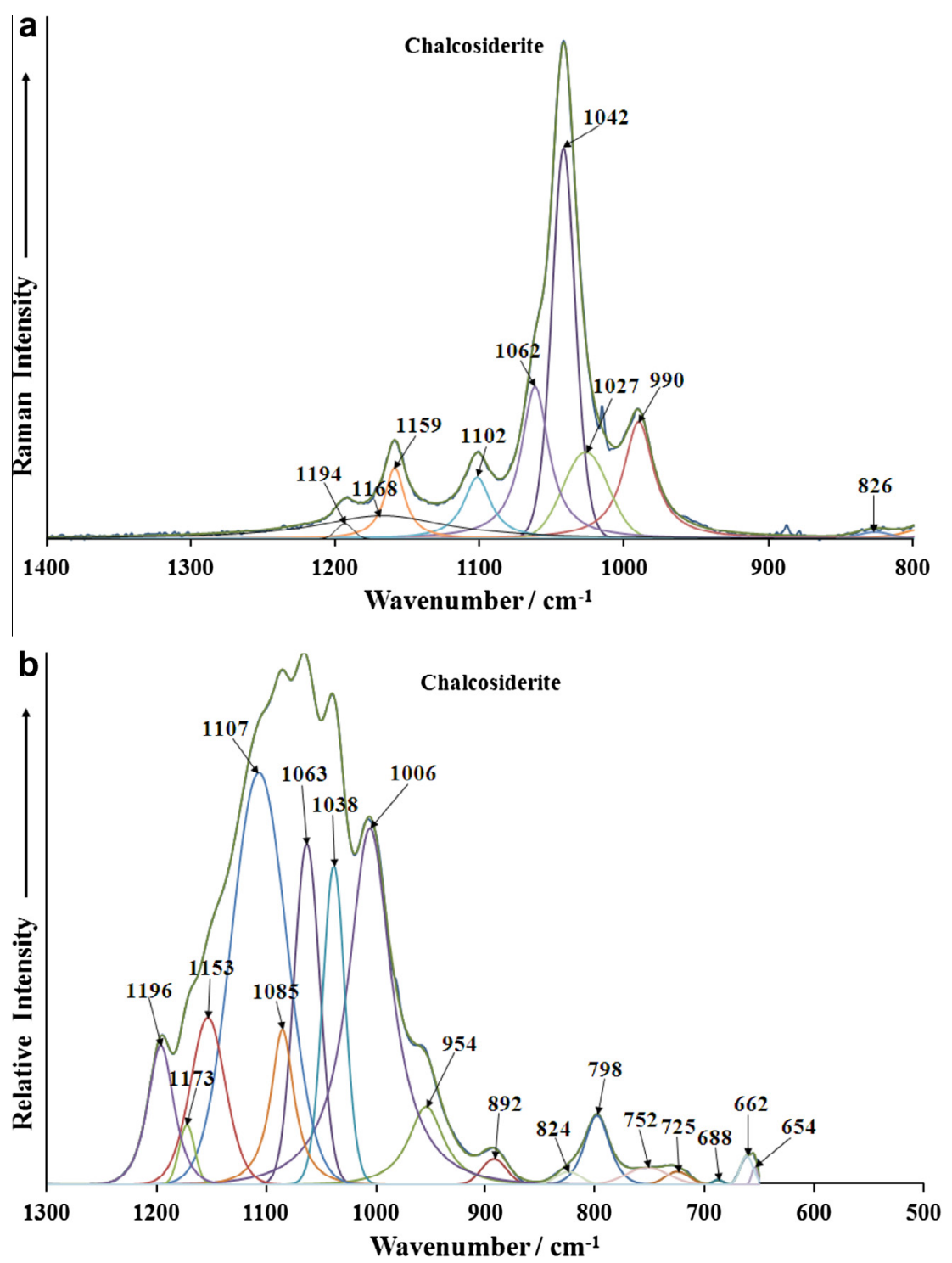

Fig. 4. (a) Raman spectrum of chalcosiderite over the $800-1400 \mathrm{~cm}^{-1}$ spectral range (b) infrared spectrum of chalcosiderite over the $500-1300 \mathrm{~cm}-1$ spectral range. 
composition, with predominance of $\mathrm{P}, \mathrm{Al}, \mathrm{Ca}, \mathrm{Fe}$ and $\mathrm{Cu}$. Minor amounts of $\mathrm{S}$ were also observed. The spectrum is shown in Fig. 2.

\section{Factor group analysis}

The factor group analysis for turquoise and related minerals is given in Tables 1 and 2 . In the structure of turquoise there are two non-equivalent phosphate, two non-equivalent water units and four non-equivalent $\mathrm{OH}$ units. Thus there are two distinct sets of water and phosphate vibrations. The lattice vibrations are represented as $\Gamma=57 \mathrm{~A}_{\mathrm{u}}+57 \mathrm{~A}_{\mathrm{g}}$. There are 36 internal phosphate vibrations and 12 internal water vibrations which make a total of 162 crystal vibrations, i.e. $\left[\mathrm{CuAl}_{6}\left(\mathrm{PO}_{4}\right)_{4}(\mathrm{OH})_{8} \cdot 4 \mathrm{H}_{2} \mathrm{O}\right] \quad N=55$ thus $3 n-3=3 * 55-3=162$ vibrations. For each hydroxyl there is one Raman active and one infrared active vibration. Thus four bands should be observed in both the Raman and infrared spectra in the $\mathrm{OH}$ stretching region.

\section{Spectroscopy}

The spectra of chalcosiderite $\left[\mathrm{CuFe}_{6}\left(\mathrm{PO}_{4}\right)_{4}(\mathrm{OH})_{8} \cdot 4 \mathrm{H}_{2} \mathrm{O}\right]$ depend on the subunits in the structure, namely the phosphate units, the water units and the hydroxyl units. Each of these units will show vibrational bands in both the Raman and infrared spectra. Some overlap of bands of the water and $\mathrm{OH}$ units may occur. One most beneficial way of studying phosphate minerals is to undertake vibrational spectroscopy. In this way, the symmetry and distortion of the phosphate units in the mineral structure can be ascertained. Further, if there are different sometimes called non-equivalent phosphate units, then vibrational spectroscopy can determine if the phosphate units are identical or different. The Raman spectrum of chalcosiderite over the $100-4000 \mathrm{~cm}^{-1}$ spectral region is displayed in Fig. 3a. This figure shows the position and relative intensity of the Raman bands. It is obvious that the less intense spectral region is over the $2600-4000 \mathrm{~cm}^{-1}$ region. This region is where the water and $\mathrm{OH}$ stretching vibrations are likely to be observed. The overall spectrum may be subdivided into sections depending upon the type of vibration being studied. The infrared spectrum over the $500-4000 \mathrm{~cm}^{-1}$ spectral range is shown in Fig. 3b. As for the Raman spectrum there are spectral regions where no intensity is observed and therefore the spectrum may be subdivided into sections depending upon the type of vibration.

The Raman spectrum in the $800-1400 \mathrm{~cm}^{-1}$ spectral range is displayed in Fig. 4a. This spectral region is the region of the phosphate stretching bands. The infrared spectrum shown in Fig. 4b, shows a complex spectral profile with overlapping bands. In the
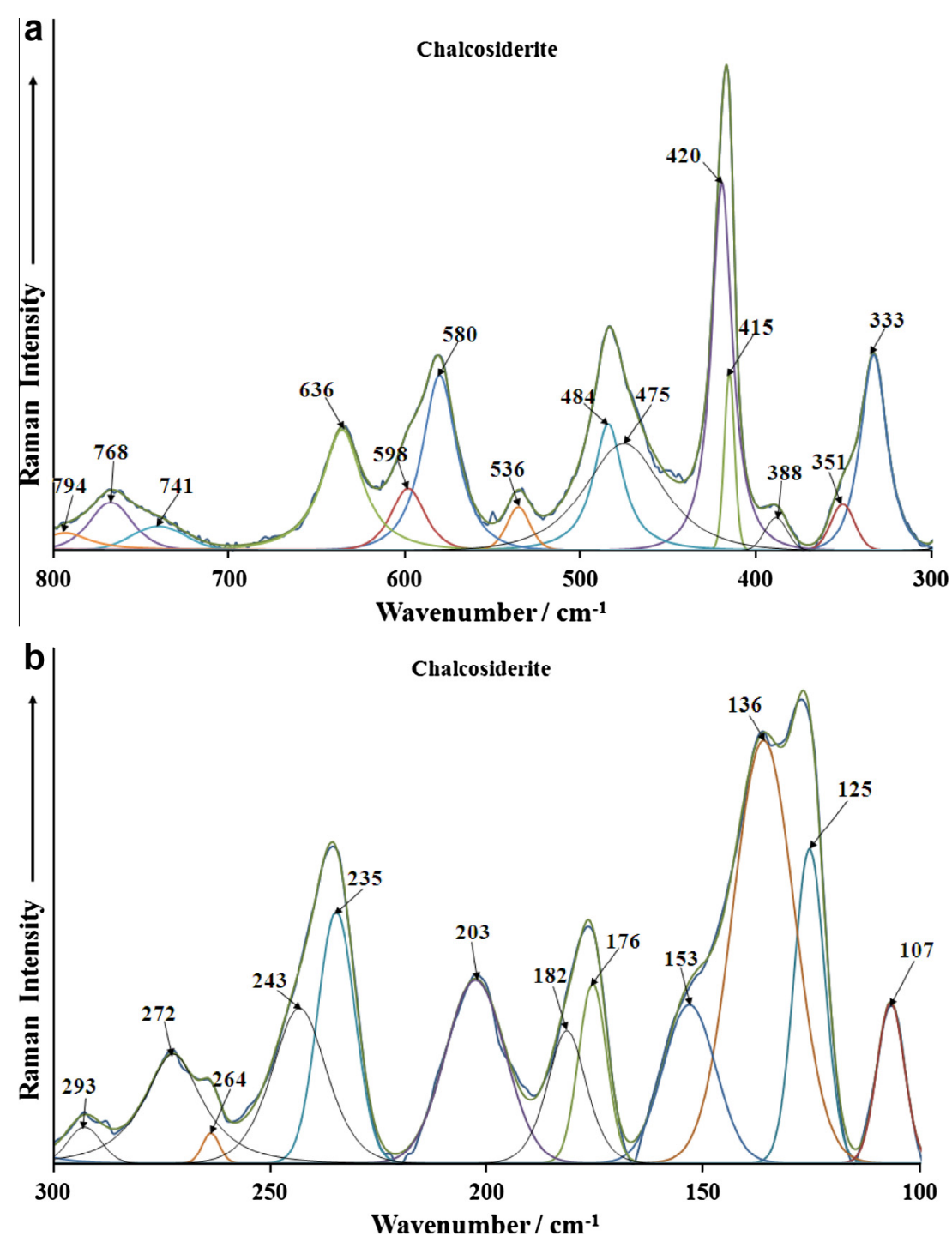

Fig. 5. (a) Raman spectrum of chalcosiderite over the $300-800 \mathrm{~cm}^{-1}$ spectral range (b) Raman spectrum of chalcosiderite over the $100-300 \mathrm{~cm}{ }^{-1}$ spectral range. 
structure of chalcosiderite there are two distinct phosphate units. This means that there should be two separate phosphate stretching vibrations. An intense Raman band is observed at $1042 \mathrm{~cm}^{-1}$ with a strong shoulder at $1062 \mathrm{~cm}^{-1}$. These bands are assigned to the $\mathrm{PO}_{4}^{3-} v_{1}$ symmetric stretching vibrations. Factor group analysis predicts there should six Raman and six infrared bands, three from each of the two independent phosphate units. Three Raman bands are found at 1102,1159 and $1194 \mathrm{~cm}^{-1}$. These bands are assigned to the $\mathrm{PO}_{4}^{3-} v_{3}$ antisymmetric stretching vibrations. A comparison may be made with the mineral turquoise $\mathrm{CuAl}_{6}\left(\mathrm{PO}_{4}\right)_{4}(\mathrm{OH})_{8} \cdot 4 \mathrm{H}_{2} \mathrm{O}$ which is isomorphous with chalcosiderite. The Raman spectrum of turquoise typically shows two symmetric stretching modes at 1066 and $1042 \mathrm{~cm}^{-1}$. The replacement of $\mathrm{Al}$ (turquoise) by $\mathrm{Fe}$ (chalcosiderite) in the structure causes a shift to lower wavenumbers. A band is observed in the Raman spectrum at around $990 \mathrm{~cm}^{-1}$. The assignment of this band is open to question. There are two possibilities (a) a hydrogen phosphate symmetric stretching mode and (b) a hydroxyl deformation mode. In the light of the previous assignment of the higher wavenumber bands the latter assignment is preferred.
The infrared spectrum (Fig. 4b) shows two bands at 1006 and $1038 \mathrm{~cm}^{-1}$ which may be assigned to the $\mathrm{PO}_{4}^{3-} v_{1}$ symmetric stretching vibrations. The observation of two symmetric stretching modes offers support to the concept of two independent phosphate units in the chalcosiderite structure. The resolved infrared components at $1063,1107,1153$ and $1196 \mathrm{~cm}^{-1}$ are attributed to the $\mathrm{PO}_{4}^{3-} v_{3}$ antisymmetric stretching vibration al modes. A comparison is made with the infrared spectrum of turquoise where three bands are observed at 1182, 1161 and $1104 \mathrm{~cm}^{-1}$. Factor group analysis predicts there should be six infrared active modes. Six bands are not observed and this is attributed to accidental degeneracy. The two sets of Raman and infrared bands from the two independent phosphate units overlap. The infrared band at $954 \mathrm{~cm}^{-1}$ may be attributed to a hydroxyl deformation mode.

The Raman spectra of chalcosiderite in the $300-800 \mathrm{~cm}^{-1}$ and $100-300 \mathrm{~cm}^{-1}$ spectral range are reported in Fig. $5 \mathrm{a}$ and b. The first spectral region is the region where the phosphate bending modes are observed. The spectrum may be divided into subsections. The spectral region between 700 and $800 \mathrm{~cm}^{-1}$ are assigned to water librational modes. According to the factor group analysis there
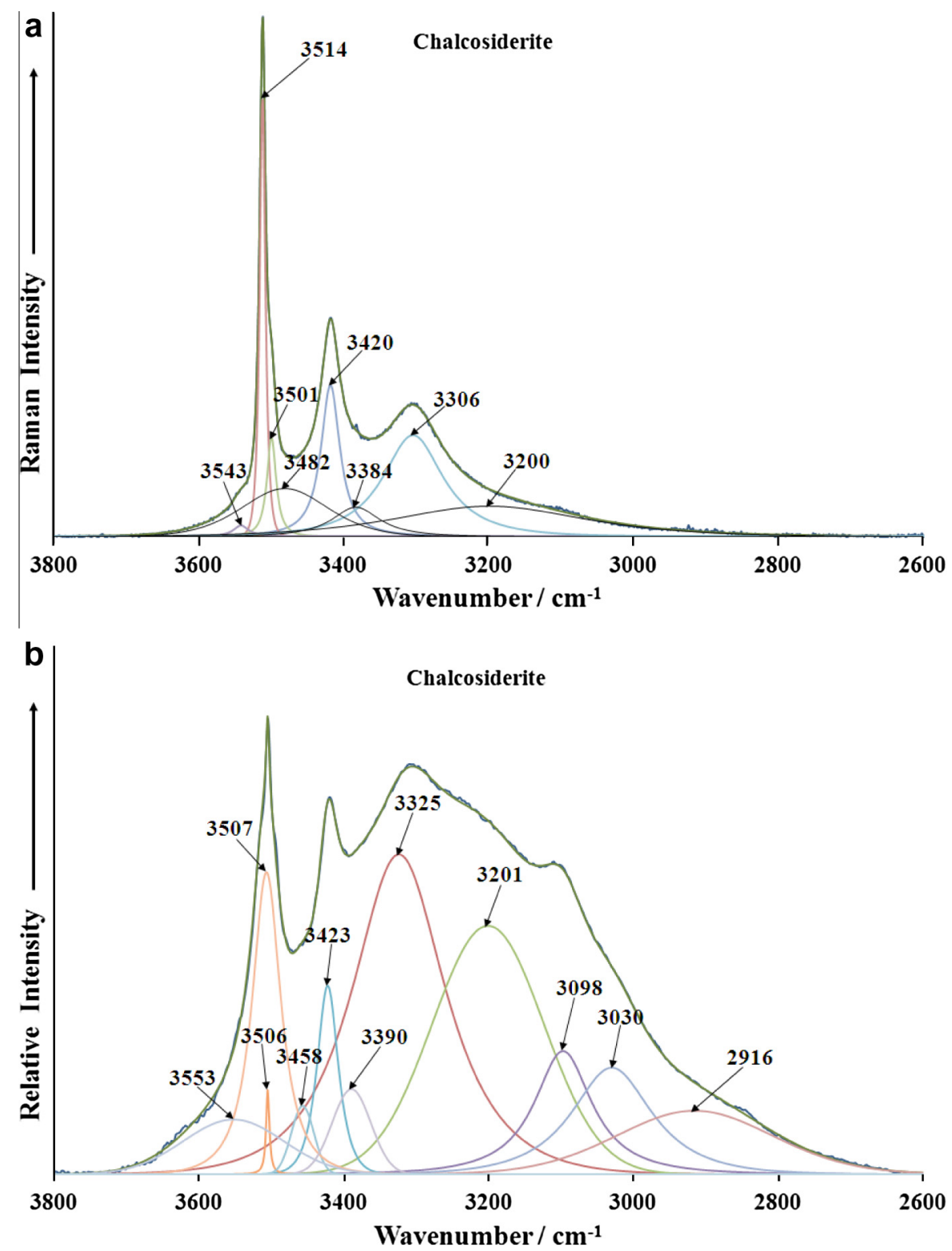

Fig. 6. (a) Raman spectrum of chalcosiderite over the $2600-4000 \mathrm{~cm}^{-1}$ spectral range (b) infrared spectrum of chalcosiderite over the $2600-4000 \mathrm{~cm}^{-1}$ spectral range. 
should be two sets of water bands. This is confirmed by the experiment in that two water librational modes are observed. In the spectral range from 500 to $700 \mathrm{~cm}^{-1}$ region, four Raman bands are observed at 536, 580, 598 and $636 \mathrm{~cm}^{-1}$. These four bands are assigned to the $v_{4}$ bending modes. The results of FGA show that at least two bending modes would be found and this is confirmed by the observation of four bending modes in the Raman spectrum. Raman bands for turquoise are observed at 550, 570, 593 and $643 \mathrm{~cm}^{-1}$. The number of bands in this spectral region confirms the existence of two non-equivalent phosphate units and the loss of degeneracy of the bending modes.

The next spectral region is from around 500 to $400 \mathrm{~cm}^{-1}$ where the phosphate $v_{2}$ bending modes are expected. Raman bands for chalcosiderite are found at $415,420,475$ and $484 \mathrm{~cm}^{-1}$. In comparison, the Raman bands for turquoise Raman bands were found at $419,439,468$ and $484 \mathrm{~cm}^{-1}$. The bands for chalcosiderite (the Fe rich compound) appear at lower wavenumbers than the Aluminium rich mineral turquoise. Raman bands for chalcosiderite are observed at 333,351 and $388 \mathrm{~cm}^{-1}$. These bands are assigned to $\mathrm{CuO}$ stretching bands. Intense Raman bands are observed in the region centred upon $330 \mathrm{~cm}^{-1}$ for turquoise. Multiple bands are also observed for turquoise. Bands in this spectral region are assigned to $\mathrm{CuO}$ and metal-oxygen stretching vibrations. Raman bands in the 100$300 \mathrm{~cm}^{-1}$ spectral range are simply defined as lattice vibrations.

The Raman spectrum of chalcosiderite in the $\mathrm{OH}$ stretching region are reported in Fig. 6a. One of the difficulties that may be predicted is the potential overlap between the $\mathrm{OH}$ stretching vibrations of the $\mathrm{OH}$ units and the water units. The Raman spectra between 3800 and $2600 \mathrm{~cm}^{-1}$ may be subdivided into two spectral regions (a) $3400-2600 \mathrm{~cm}^{-1}$ and (b) $3800-3400 \mathrm{~cm}^{-1}$. The first spectral region is where the water $\mathrm{OH}$ stretching bands are observed and the second region is where the $\mathrm{OH}$ stretching bands of the hydroxyl units. FGA predicts two independent water units and four $\mathrm{OH}$ units. The vibrational modes are both Raman and infrared active. Thus it is predicted that there should be a four $\mathrm{OH}$ symmetric stretching vibrations from the $\mathrm{OH}$ units and two from the water units. A very intense band is observed at $3514 \mathrm{~cm}^{-1}$ with a shoulder band on the lower wavenumber side together with a small low intensity band at $3543 \mathrm{~cm}^{-1}$. There is also a broad band at $3482 \mathrm{~cm}^{-1}$. These bands are attributed to the $\mathrm{OH}$ stretching vibrations of the $\mathrm{OH}$ units. Two strong Raman bands are found at 3306 and $3420 \mathrm{~cm}^{-1}$ and are assigned to the water stretching modes. For turquoise, Raman bands attributed to water stretching vibrations are found at 3276 and $3072 \mathrm{~cm}^{-1}$.

The infrared spectrum of chalcosiderite in the $2600-3800 \mathrm{~cm}^{-1}$ spectral range is displayed in Fig. 6b. The spectrum displays complexity with significant band overlap. The assignment of the bands is difficult because of this band overlap. Infrared bands are noted at $3458,3506,3507$ and $3553 \mathrm{~cm}^{-1}$. These bands are ascribed to the $\mathrm{OH}$ stretching vibrations. It is likely the $\mathrm{OH}$ vibrations in the same band position because of accidental degeneracy. Broad infrared bands observed at 3030, 3098, 3201, 3325 and $3390 \mathrm{~cm}^{-1}$ are ascribed to water stretching vibrations.

Studies have shown a strong correlation between $\mathrm{OH}$ stretching frequencies and both $\mathrm{O} \cdots \mathrm{O}$ bond distances and $\mathrm{H} \cdots \mathrm{O}$ hydrogen bond distances [19-22]. Libowitzky showed that a regression function can be employed relating the hydroxyl stretching frequencies with regression coefficients better than 0.96 using infrared spectroscopy [23]. The function is described as: $v_{1}=(3592-304) \times 10^{9 \frac{-d(0-O)}{0.1321}} \mathrm{~cm}^{-1}$. Thus $\mathrm{OH}-\mathrm{O}$ hydrogen bond distances may be calculated using the Libowitzky empirical function. The values of 3306 and $3420 \mathrm{~cm}^{-1}$ give hydrogen bond distances of $2.74_{5}$ and $2.81_{2} \AA$. The estimated hydrogen bond distances are difficult to obtain from $\mathrm{X}$-ray diffraction. Values can be obtained from neutron diffraction studies but such studies of minerals are rare. Hydrogen positions may be inferred from difference plots in XRD studies. Calculations using the Raman bands at 3501, 3514 and $3543 \mathrm{~cm}^{-1}$ give hydrogen bond distances of $2.89_{6}, 2.91_{7}$ and $2.97_{8} \AA$. The hydrogen bond distances involving the $\mathrm{OH}$ units are longer than those involving the water units.

\section{Conclusions}

A chalcosiderite mineral from Siglo XX mine, Bolivia were analysed by Raman and infrared spectroscopy. The sample composition was analysed by electron probe and the exact formula determined. The vibrational spectra were related to the structure of the mineral. A comparison between the spectra of chalcosiderite and turquoise was made. The mineral chalocsiderite has two independent phosphate units in the unit cell. This results in increased complexity in the spectra resulting in doubling of many of the characteristic phosphate bands.

Vibrational spectroscopy enabled an assessment of the molecular structure of the mineral chalcosiderite.

\section{Acknowledgments}

The financial and infra-structure support of the Discipline of Nanotechnology and Molecular Science, Science and Engineering Faculty of the Queensland University of Technology, is gratefully acknowledged. The Australian Research Council (ARC) is thanked for funding the instrumentation. The authors would like to acknowledge the Center of Microscopy at the Universidade Federal de Minas Gerais (http://www.microscopia.ufmg.br) for providing the equipment and technical support for experiments involving electron microscopy. R. Scholz thanks to FAPEMIG - Fundação de Amparo à Pesquisa do Estado de Minas Gerais, (Grant No. CRA APQ-03998-10).

\section{Appendix A. Supplementary material}

Supplementary data associated with this article can be found, in the online version, at http://dx.doi.org/10.1016/j.saa.2013.02.023.

\section{References}

[1] A. Mandarino, Fleischer's glossary of mineral species, mineralogical record, Tuscon, Arizona, USA, 1999.

[2] E.R. Zalinski, Econ. Geol. 2 (1907) 464-492.

[3] W.T. Schaller, J. Washington Acad. Sci. 1 (1911) 58-59.

[4] F.W. Clarke, The data of geochemistry, third ed., vol. 616, US Geological Survey Bulletin, 1916, p. 821.

[5] H. Steinmetz, Zeit. Krist. Min. 55 (1916) 376-377.

[6] A.M. Hewitt, Chem. Eng. Min. Rev. 11 (1919) 103-106.

[7] F.K. Mayer, Chem. Erde 9 (1935) 311-317.

[8] D. McConnell, Am. J. Sci. 240 (1942) 649-657.

[9] A.R. Graham, University of Toronto Studies, Geological Series 52 (1948) 39-53.

[10] H. Cid-Dresdner, Am. Min. 50 (1965) 227-231.

[11] R.S.W. Braithwaite, Min. Rec. 12 (1981) 349-353.

[12] G.R. Hunt, J.W. Salisbury, C.J. Lenhoff, Mod. Geol. 3 (1972) 121-132.

[13] X.-Y. Yang, Y.-F. Zheng, X.-M. Yang, X. Liu, K. Wang, Neues Jahr. Min. (2003) 97-112.

[14] R.L. Frost, W. Martens, P.A. Williams, J.T. Kloprogge, Min. Mag. 66 (2002) $1063-$ 1073.

[15] R.L. Frost, W.N. Martens, T. Kloprogge, P.A. Williams, Neues Jahr. Min. (2002) 481-496.

[16] R.L. Frost, P.A. Williams, W. Martens, J.T. Kloprogge, P. Leverett, J. Raman Spectrosc. 33 (2002) 260-263.

[17] V.C. Farmer, Mineralogical Society Monograph 4: The Infrared Spectra of Minerals, The Mineralogical Society, London, 1974.

[18] J. Hyrsl, A. Petrov, Min. Rec. 37 (2006) 117-120.

[19] J. Emsley, Very strong hydrogen bonding, Chem. Soc. Rev. 9 (1980) 91-124.

[20] H. Lutz, Struct. Bonding 82 (1995) 85-103.

[21] W. Mikenda, J. Mol. Struct. 147 (1986) 1-15.

[22] A. Novak, Struct. Bonding 18 (1974) 177-216.

[23] E. Libowitsky, Monat. Chem. 130 (1999) 1047-1049. 